\title{
System Analysis and Solution of Energy Efficiency Problems in Machine-Building Production
}

\author{
A.A. Gavrilova ${ }^{1}$, E.A. Matveeva ${ }^{2,}$, , and A.G. Salov ${ }^{1}$ \\ ${ }^{1}$ Samara State Technical University, Samara, RF \\ ${ }^{2}$ Volga State University of Telecommunications and Informatics, Samara, RF
}

\begin{abstract}
The article discusses application of system analysis to identify and solve the problems of energy efficiency of machine-building enterprises. The increase in the efficiency of a machine-building enterprise is influenced by many factors, among which tariffs and prices for energy services have a significant impact. The increase in tariffs for these services has a direct impact on the increase in cost. Energy efficiency objectives also include: high energy capacity of products; insufficient efficiency of generation, transportation and distribution of energy resources; low reliability of power supply; insufficient volume or low reliability of information on the energy infrastructure operation. As a result of the system analysis, directions have been identified that enable one to increase energy efficiency, which leads to a decrease in the cost of production, and, consequently, to an increase in the profit of the enterprise. Directions for increasing the energy efficiency of machine-building enterprises can be identified as a result of system studies of the activities of all divisions of the main, auxiliary and service industries. The greatest effect from energysaving measures is achieved in the process of rational energy consumption, which is advisable to implement at machine-building enterprises. Reduced production output caused by the global economic crisis that began in 2008 and the impact of the 2020-2021 pandemic have resulted in the equipment operation at reduced loads and in off-design modes, which in turn has led to the auxiliary equipment consuming almost the same amount of energy as at nominal performance. This circumstance leads to an increase in costs. A mathematical model has been developed, in which a machine-building enterprise is considered as a set of functional elements and components with a hierarchical structure of connections between them, described in the form of a ' 6 -tuple'.
\end{abstract}

\section{Introduction}

For the study of complex systems and objects, such as machine-building enterprises, operating in changing conditions, the most effective application is the system analysis methodology, which makes it possible to identify fundamental, system-wide regularities of

${ }^{*}$ Corresponding author: helen_matveeva@mail.ru 
enterprise functioning, to determine their relationship with the external environment and other objects, to improve structures and management methods, to assess the complex socioeconomic efficiency, to study the use of the most significant business resources: labor, information, capital, energy, material, raw material, etc. Using the system methodology, machine-building enterprises are considered from the point of view complex analysis and modeling of production and economic systems as complex developing objects of management.

According to the postulates set forth in the national project 'Increase of productivity', machine-building enterprises are carrying out work to replace obsolete technologies and equipment. These measures can significantly increase labor productivity, reduce energy consumption in production and, accordingly, make products more competitive $[2,3,8]$.

A systematic analysis of the activities of industrial and economic objects is based on a comprehensive study of specific features and problems of the efficiency of enterprises' activity, which in a determining way depends on the quality of management of the main production at all stages and levels.

Increasing the efficiency of a machine-building enterprise as a whole, which determines its competitiveness, is its main goal. An important component of achieving the goal is to reduce the cost of production, which largely depends on tariffs and prices for energy resources. A serious problem is a significant increase in the energy component in the cost of production, which reaches $40 \%[1,4-8,10]$.

\section{Research methodology}

The survey showed that machine-building enterprises are more and more moving to a small-scale type of production, which is dictated by market requirements. In relation to this trend, the systems of organizational management of production of machine-building enterprises can be attributed to the class of the most labor-intensive and complex. Smallscale production is characterized by a large and varied range of structurally complex products; a variety of technological processes for processing parts; a wide range of production cycles for the manufacture of parts; a large range of materials and components used in the production; a high degree of interconnection and interdependence between workshops at all stages of production; a large number and variety of detail-operations attached to the site; low repeatability of the part-operations performed for the planned period; a wide range of processed operations; a significant number and duration of equipment re-adjustments when processing a batch from one part to another, etc.

As shown by system analysis of the management systems operating at enterprises, the greatest number of problems arises when solving the tasks of planning production activities, such as logistics, as well as the tasks of increasing energy efficiency of production [2,3,9]. When analysing energy efficiency of production systems, one should start with the activities of end consumers - machine-building enterprises, then proceed to the distribution system, and only lastly, one should investigate the energy conversion stage.

Modelling enables one to consider a machine-building enterprise as a set of functional elements and components with a hierarchical structure of connections between them, described in the form of a ' 6 -tuple':

$$
M_{l}=\left\{Q_{l}, P_{l m}, S_{l m k}, F_{l}, N_{l m}, J_{l m k}\right\},
$$

where $\quad-Q_{l}$ - essence of the problems; - $P_{l m}$ - basic problem decomposition structures $M_{l} ;-S_{l m k}$ - functional models and tasks formalizing isolated structures $P_{l m} ;-F_{l}-$ methodological means of solving the problem $M_{l} ;-N_{l m}$ - methodological means of solving 
the problem $P_{l m}$ and functional tasks $S_{l m k} ;-J_{l m k}$ - collection of information needed to solve problems $P_{l m}$ and tasks $S_{l m k}$ by methods $N_{l m}$. [2,3]

A graphical representation of the model is shown in Figure 1.

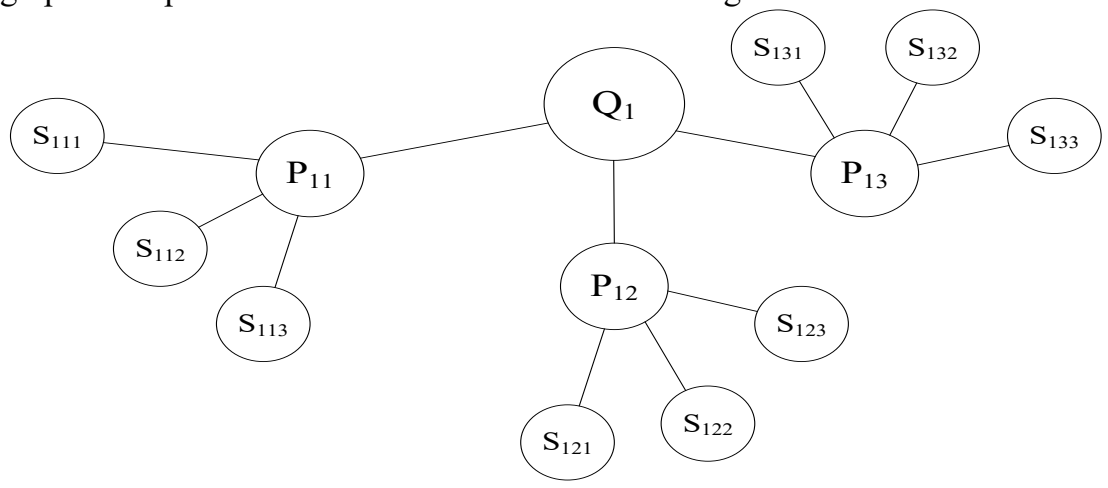

Fig. 1. Machine-building enterprise as an object of management

In this model, the essence of $Q_{l}$ is the specificity of production from the standpoint of management theory. Structural models: - $P_{11}$ - consistency of enterprise plans; - $P_{12}$ variety of technological processes and operations, many routes of movement of parts; - $P_{13}$ - interconnection and interaction of production, management, financial, energy and logistics factors.

The composition of functional models and tasks $S_{l m k}$ is considered, including - $S_{111}-$ $S_{113}$ - plans of the enterprise at various levels; - $S_{121}-S_{123}$ - tasks related to the production process; - $S_{131}-S_{133}$ - management tasks related to energy efficiency and improvement of product manufacturing technologies.

The methodology $F_{1}$ is the concept of a systematic analysis of machine-building production problems.

Methods for solving problems were: $N_{11}$ - active systems theories; $N_{12}$ - operations research; $N_{13}$-diagnostics and identification.

Information $J_{1 m k}$ used in the model: - $J_{111}-J_{113}$ - associated with the volumes of products inlet; $-J_{121}--J_{123}-$ associated with the list of equipment and manufacturing technology; - $J_{131}-J_{133}$ - components of material and energy costs.

Manufacturing technologies used in mechanical engineering enterprises have a direct impact on energy efficiency.

As a result of the analysis, it was revealed that reduction in the cost of production is associated with the solution of a number of problems, including: high energy consumption of products; insufficient efficiency of generation, transport and distribution of energy resources; low reliability of power supply; insufficient volume or low reliability of information on the energy infrastructure operation; excessive energy intensity of morally and physically obsolete equipment of technological processes. The main of them is high energy intensity of products, since it affects the increase in the cost of production and, as a result, the decrease in the competitiveness of the enterprise [8].

To implement production processes, machine-building enterprises have complexes of workshops, which are the main structural unit of the enterprise (Fig. 2). 


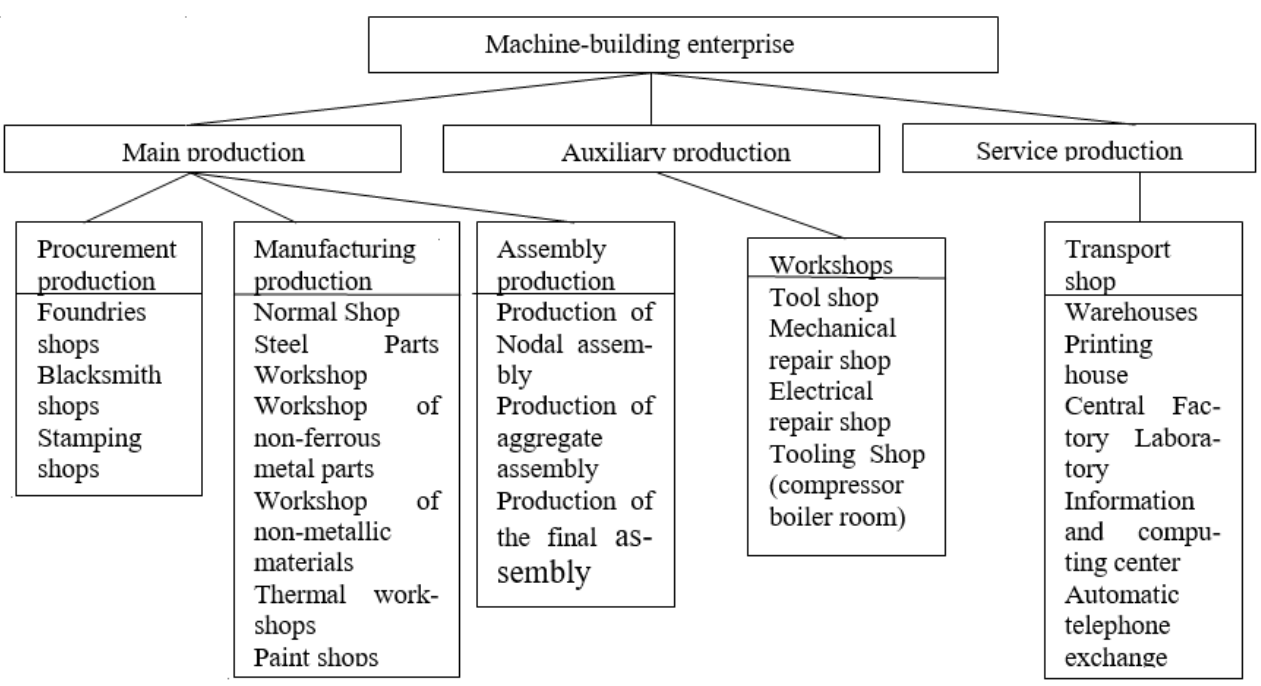

Fig. 2. The structure of a machine-building enterprise

Each workshop, in turn, has a complex structure with division into production and auxiliary sections, which are also the main structural elements of the enterprise $[2,3,9]$. Efficiency of the enterprise as a whole, in a decisive way, depends on the organization of management of production business processes at all stages and levels, in conjunction with resource, material and financial support [2-4,8].

Directions for increasing the energy efficiency of machine-building enterprises can be identified as a result of system studies of the activities of all divisions of the main, auxiliary and service industries. The greatest effect from energy-saving measures is achieved in the process of rational energy consumption, which is advisable to implement at machinebuilding enterprises.

The distribution of each energy resource among consumers and compilation of energy balances makes it possible to single out main consumers of energy resources in workshops and estimate the value of their energy consumption. Large consumers (boilers, stoves, heaters, heating and ventilation systems, compressors, pumps, etc.) should be studied in detail, i.e. it is necessary to draw up their energy balances, taking into account their work schedule, load, etc., which will determine ways to reduce energy losses and improve efficiency of the equipment. Thus, only on basis of a systematic approach is it possible to increase the energy efficiency of machine-building enterprises.

For example, if the load of technological equipment is not constant, then it makes sense to use variable-frequency drives on the motors of pumps, fans, and smoke exhausters, which will significantly save energy when the auxiliary equipment operates at a reduced load.

\section{Research results. Analysis of the organization of industrial enterprises' power supply}

The energy component of production cost is accumulated in the processes of transformation, distribution and use of energy. Over the past thirty years, the specific energy consumption of generation has increased by almost 1.5 times, largely due to a decrease in industrial steam consumption, which has caused a decrease in the energy efficiency of both energy production and energy consumption. The value of energy component is also influenced by the energy intensity of production, the value of tariffs for 
heat and electricity, and the total consumption of various types of energy by the enterprise. Analysis of these data enables one to identify possible ways to increase energy efficiency of energy conversion, reduce the cost of energy generation, which in turn will affect competitiveness of machine-building enterprises by reducing the energy component in the cost of production $[7,8]$.

To improve energy efficiency, the generation of energy resources needs industrial consumers of a continuous cycle with high technical and economic indicators of production processes.

The energy system is divided into separate generating, network and sales companies, a lot of energy resellers have appeared, which, in general, leads to a significant increase in the cost of energy resources.

Let us analyze the activities of energy production, which provides energy supply to industrial consumers, based on the abstracted infrastructure model of the energy system, shown in Figure 3 [1].

Internal and external activities of a generating company are the main subsystems of the infrastructure model, their interaction determines functioning of the power system [11].

1. Internal activity includes blocks of 'production resources', 'energy resources'; 'technological production'; 'control systems' of power facility and products of a power plant (block 'generated energy').

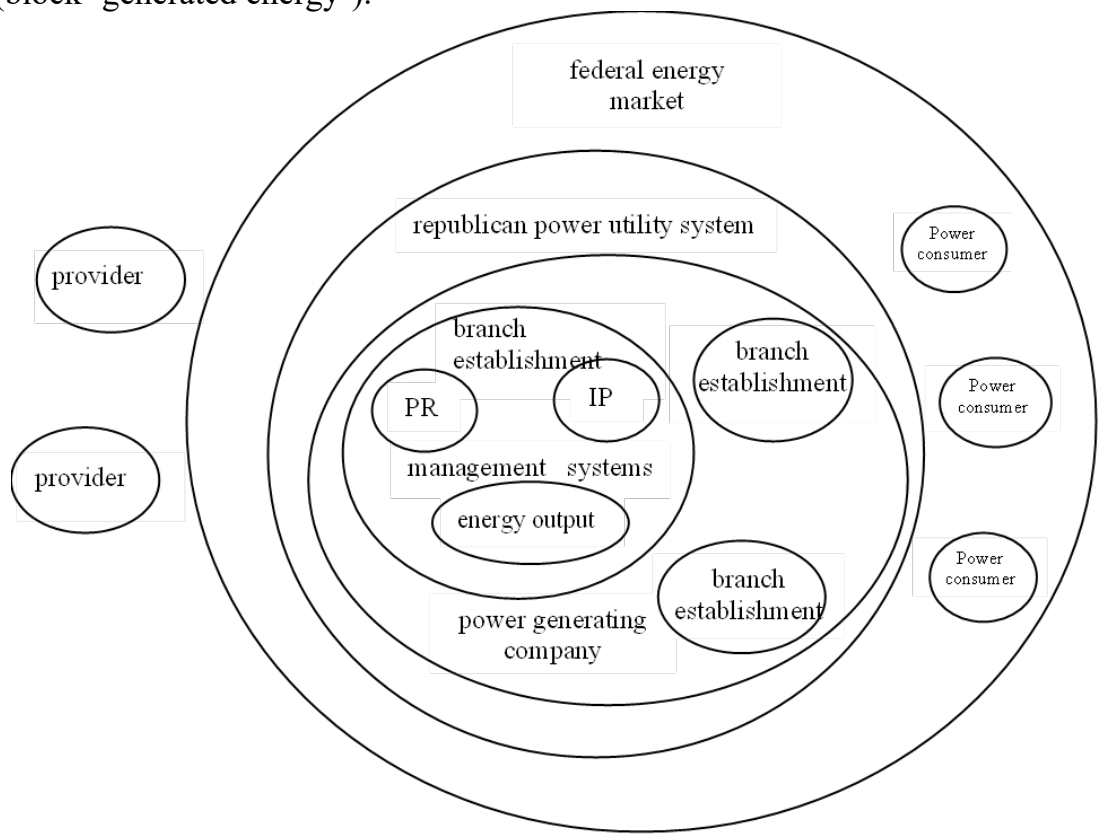

Fig. 3. Infrastructure model of a generating company. IP - industrial processes, PR - production resources

2. The external activity of a generating company is a process of interaction with the external environment. The block 'republican energy system' includes federal network enterprises, regional network enterprises, generating and power supply organizations. The 'energy consumers' include industrial enterprises, state and public institutions, and the housing and household sector.

The power system, connected with other generating enterprises and suppliers that generate electricity, has the opportunity, in case of economic feasibility, either to supply 
excess electricity to the federal market, or to purchase electricity from the unified power system.

One of the ways to improve energy efficiency is to reduce the consumption of electricity for the own needs of energy production, which is generated by a generating company. The amount of electricity consumption for own needs is up to $13 \%$ of the generated electricity, which is 2-3 times higher than the standard value.

Reducing own electrical needs can be achieved by optimizing and modernizing the composition of the existing main and auxiliary equipment; the use of frequency control of electric drives of motors for equipment operating for a long time in variable modes with low load.

In particular, at one of the energy enterprises, the installation of hydraulic couplings on the drives of a group of feed pumps made it possible to reduce electricity consumption for own needs by $17 \%$ [11].

\section{Discussion of the results. Management of the power system of an enterprise}

The main task of power system management, taking into account external influences, is to highlight external significant factors when solving the following internal problems.

1. Energy production with the highest economic indicators. At the same time, it is necessary to produce energy in the amount that is required by consumers at the moment. This condition imposes rather severe restrictions on the choice of operating modes of power equipment.

2. Timely provision of the power system with the necessary production resources in real time. The specificity of using gas as a fuel makes the provision of energy production a continuous process that requires taking into account many influencing factors.

3. Ensuring uninterrupted operation of the main and auxiliary equipment of generating enterprises. Accidents at power facilities interrupt the power supply process, lead to a power outage to consumers, and, as a result, disrupt the uninterrupted operation of industrial (machine-building) enterprises.

To ensure the operation of subsystems, it is necessary to organize control of the main and auxiliary technological parameters that characterize the processes of energy production. At present, the control and measurement of most of the characteristics is carried out constantly with the help of automated technical means, or by carrying out periodic manual measurements in the absence of automated control means.

To increase the integrated efficiency of energy production in the context of constant transformations in the principles of organization and methods of management of energy enterprises, it is necessary, on basis of system approaches and methods of mathematical modeling, to study internal and external production and technological relations and parameters of the state of enterprises, to evaluate the efficiency of functioning of the generating company, taking into account the contribution of various resources to the final indicators of the energy system [3].

In addition, it is necessary to introduce energy-efficient technologies, including the installation of energy-saving equipment and implementation of energy-saving measures; energy saving in buildings and structures, which is a set of measures aimed at reducing the volume of energy resources used while maintaining the volume of products manufactured, work performed, etc.; organizational energy saving, providing for an increase in the culture of energy saving and organizational measures to regulate energy consumption during the day $[1,8]$. These measures make it possible to see the increased costs of energy resources due to low loading of mechanisms and equipment, irregular operation of the main 
equipment associated with the duration of downtime without disconnecting from power sources $[2,3,8]$.

\section{Conclusion}

Solving the problem of increasing the efficiency of using energy resources can significantly reduce the energy component in the cost of production, increase competitiveness of the enterprise. To determine the possible energy consumption at all stages of product life cycles, it is necessary to conduct a systemic energy survey of all stages of machine-building production $[1,8]$

The analysis of production systems should start with the end users, then proceed to the distribution system, and only lastly investigate the stages of energy conversion.

The systematic approach revealed dependence of the energy efficiency of distribution and energy conversion processes on a decrease in final consumption, which leads to a decrease in distribution losses, since less energy is required for transmission. It is possible to reduce energy consumption through the use of automation, modernization of technological processes and reduction of losses.

In general, organization and management of power supply of a machine-building enterprise is a complex process that requires a comprehensive study of influencing factors, a study of system connections and patterns of functioning and development of facilities, taking into account changing economic conditions.

\section{References}

1. A.A. Gavrilova, A.G. Salov. Systemic analysis of energy systems in the new economy, 2020 International Multi-Conference on Industrial Engineering and Modern Technologies (FarEastCon), Vladivostok, 2020, pp. 1-4, doi: 10.1109/FarEastCon50210.2020.9271638.

2. E.A. Matveeva, S.G. Simagina. Functional management of the economic activities of industrial systems (article).MATEC Web of Conferences. - No. 129. - 2017, pp. 1-5, 04007 DOI:10.1051/matecconf/201712904007 https://www.matecconferences.org/articles/matecconf/abs/2017/43/contents/contents.html

3. E.A. Matveeva, S.G. Simagina. Manufacturing process optimization at enterprises (article). Key engineering materials. - 2016. - 534 p. - Vol. 684, pp. 409-413

4. GOST 27322-87, Energy balance of an industrial enterprise. Basic Provisions.

5. GOST 31607-2012, Energy saving. Regulatory and methodological support. Basic Provisions.

6. GOST R 51750-2001, Methodology for determining energy consumption in the manufacture of products and provision of services in technological energy systems. General provisions (p. 6.2. The nature of possible energy losses and the direction of their reduction at product life cycle stages and service execution).

7. E.E. Merker. Energy saving in industry and energy analysis of technological processes. Textbook / E.E. Merker. - M.: TNT, 2014. - 316 p.

8. T.S. Meshcheryakova. Analysis of energy consumption of industrial enterprises in modern conditions http://www.abok.ru/for_spec/articles.php?nid=615

9. F.I. Paramonov. Theoretical foundations of production management / Paramonov F.I., Soldak Yu.M. - Publisher: BINOM. LZ. 2009. - 280 p. 
10. M.V. Polyanichko. Methodological approaches to managing energy efficiency of an enterprise // Modern management technologies. ISSN 2226-9339. - No. 3 (75). Article number: 7503. Publication date: 2017-03-06. Access mode: https://sovman.ru/article/7503/

11. A.A. Gavrilova, A.G. Salov. System analysis and modeling of infrastructure of production activities of generating companies 2019 XXI International Conference Complex Systems: Control and Modeling Problems (CSCMP) 3-6 Sept. 2019 DOI: $10.1109 / \mathrm{CSCMP} 45713.2019 .8976680$ 